\title{
Oral-facial-digital syndrome type IX in a patient with Dandy-Walker malformation
}

Kazushige Nagai, Masayoshi Nagao, Michiko Nagao, Seika Yanai, Kimio Minagawa, Yoshio Takahashi, Yasuo Takekoshi, Akihito Ishizaka, Yoshihiro Matsuzono, Osamu Kobayashi, Tsutomu Itagaki

Department of

Paediatrics, National

Sanatorium Otaru

Hospital, Otaru, Japan

K Nagai

M Nagao

M Nagao

Department of Paediatrics, Hokkaido

Children's Hospital and Medical Centre, Otaru, Japan

$S$ Yanai

K Minagawa

Department of

Neurosurgery,

Hokkaido Children's

Hospital and Medical

Centre, Otaru, Japan

Y Takahashi

Department of

Paediatrics, Chitose

City General Hospital,

Chitose, Japan

Y Takekoshi

A Ishizaka

Y Matsuzono

Department of

Paediatrics, Yamagata

Prefectural Kahoku

Hospital, Japan

O Kobayashi

Yamabe Children's

Clinic, Japan

$T$ Itagaki

Correspondence to: Dr Nagai, Otaru Kyokai

Hospital, 1-6-15 Suminoe,

Otaru, Hokkaido 047, Japan.

Received 21 May 1997

Revised version accepted for publication 6 October 1997
Abstract

We report a girl with oral, facial, and digital anomalies including multiple alveolar frenula, lobulated tongue with nodules, a posterior cleft palate, hypertelorism, a prominent forehead with a large anterior fontanelle, and postaxial polydactyly in both hands and the right foot, features compatible with the oral-facial-digital syndrome (OFDS). In addition, she had bilateral microphthalmia, optic disc coloboma, and retinal degeneration with partial detachment, thus establishing a diagnosis of OFDS type IX. Dandy-Walker malformation and retrobulbar cysts were observed on MRI. These additional malformations have not been reported in OFDS type IX. The frequent apnoeic spells which occurred immediately after birth were relieved after cystoperitoneal shunt implantation for hydrocephalus. Considering our case and previous reports of OFDS type IX, including two male sibs, a boy born to consanguineous

parents, and three females, inheritance is probably autosomal recessive.

(F Med Genet 1998;35:342-344)

Keywords: OFDS type IX; Dandy-Walker malformation; retrobulbar cysts; apnoeic spells

The oral-facial-digital syndromes (OFDS) are characterised by congenital malformations of the oral cavity, face, and digits. ${ }^{1-7}$ Cardinal features are lobulated tongue, cleft lip/palate, anomalies of hands and feet (pre- and postaxial polydactyly, syndactyly, brachydactyly), hypertelorism, and nasal anomalies. At least nine different types of OFDS have been recognised by Toriello. ${ }^{7}$ Several distinct patterns of inheritance have been reported, suggesting that variability in OFDS is likely to be the result of genetic heterogeneity. Recently, a new type of OFDS, type IX (originally reported as type VIII), has been described in which retinal abnormalities (retinochoroidal lacunae of colobomatous origin) were novel findings. ${ }^{1}$ Since

Table 1 Comparative features in the oral-facial-digital syndrome type IX

\begin{tabular}{|c|c|c|c|c|c|c|c|}
\hline \multirow[b]{2}{*}{ Clinical features } & \multicolumn{2}{|c|}{ Gurrieri et al ${ }^{l}$} & \multirow{2}{*}{$\begin{array}{l}\text { Famieson } \\
\text { and Collins }{ }^{2}\end{array}$} & \multirow{2}{*}{$\begin{array}{l}\text { Nevin et } \\
a l^{3}\end{array}$} & \multirow{2}{*}{$\begin{array}{l}\text { Stevens and } \\
\text { Marsh }^{4}\end{array}$} & \multirow{2}{*}{$\begin{array}{l}\text { Sigaudy } \\
\text { et al }\end{array}$} & \multirow[b]{2}{*}{ Present case } \\
\hline & Case 1 & Case 2 & & & & & \\
\hline Sex & $\mathbf{M}$ & $\mathbf{M}$ & $\mathbf{M}$ & $\mathbf{F}$ & $\mathrm{F}$ & $\mathrm{F}$ & $\mathrm{F}$ \\
\hline Age & $27 \mathrm{y}$ & $21 \mathrm{y}$ & $2 \mathrm{mth}^{\star}$ & $22 y$ & $5 y$ & $6 \mathrm{mth}$ & 1 y $5 \mathrm{mth}^{\star}$ \\
\hline Height (centile) & $<3$ & $<3$ & 50 & $<50$ & $\mathrm{U}$ & $<3$ & $<3$ \\
\hline Head circumference (centile) & $<3$ & $<3$ & $<3$ & $<50$ & $\mathrm{U}$ & $<3$ & 50 \\
\hline Mental retardation & Mild & Mild & $\mathrm{U}$ & - & Severe & Severe & Severe \\
\hline \multicolumn{8}{|l|}{ Oral anomalies } \\
\hline Multiple frenula & - & + & + & + & + & + & + \\
\hline Bifid tongue & + & - & + & + & - & - & - \\
\hline Lobulation of tongue & - & + & + & + & + & + & + \\
\hline Lobulation of oral cavity & - & - & - & + & + & - & - \\
\hline Highly arched/cleft palate & + & - & + & + & + & - & + \\
\hline Abnormal teeth & + & - & - & + & - & - & + \\
\hline \multicolumn{8}{|l|}{ Facial anomalies } \\
\hline Broad/bifid nasal tip & - & - & + & + & + & - & - \\
\hline Cleft lip & + & + & + & + & - & + & - \\
\hline Hypertelorism & - & - & + & - & + & + & + \\
\hline Synophrys & + & + & - & - & - & + & - \\
\hline Abnormal ears & - & - & + & + & + & - & + \\
\hline \multicolumn{8}{|l|}{ Hand anomalies } \\
\hline Brachydactyly & + & - & - & - & - & - & - \\
\hline Syndactyly & + & - & + & - & - & - & - \\
\hline Polydactyly & - & - & + & - & - & - & + \\
\hline Clinodactyly & - & - & + & + & + & - & - \\
\hline Camptodactyly & - & + & - & - & - & - & - \\
\hline \multicolumn{8}{|l|}{ Foot anomalies } \\
\hline Broad/bifid hallux & + & + & + & + & + & + & - \\
\hline Syndactyly & + & - & - & + & - & - & - \\
\hline Polydactyly & - & - & - & - & - & - & + \\
\hline Pes planus & + & + & - & + & - & - & - \\
\hline Retinal abnormalities & + & + & + & + & + & + & + \\
\hline Microphthalmos & - & - & - & - & + & - & + \\
\hline CNS abnormalities & + & - & + & - & - & + & + \\
\hline Seizures & - & - & + & + & + & - & + \\
\hline Abnormal epiglottis & + & - & - & - & + & - & + \\
\hline Inheritance & AR or $\mathrm{XR}$ & $\mathrm{AR}$ or $\mathrm{XR}$ & AR & $\mathrm{AR}$ & $\mathrm{AR}$ & AR & $\mathrm{AR}$ \\
\hline
\end{tabular}

$\mathrm{AR}=$ autosomal recessive inheritance; $\mathrm{XR}=\mathrm{X}$ linked recessive inheritance; $+=$ present; $-=$ absent; ${ }^{\star}=$ died at the age indicated $\mathrm{U}=$ unknown; $\mathrm{CNS}=$ central nervous system 

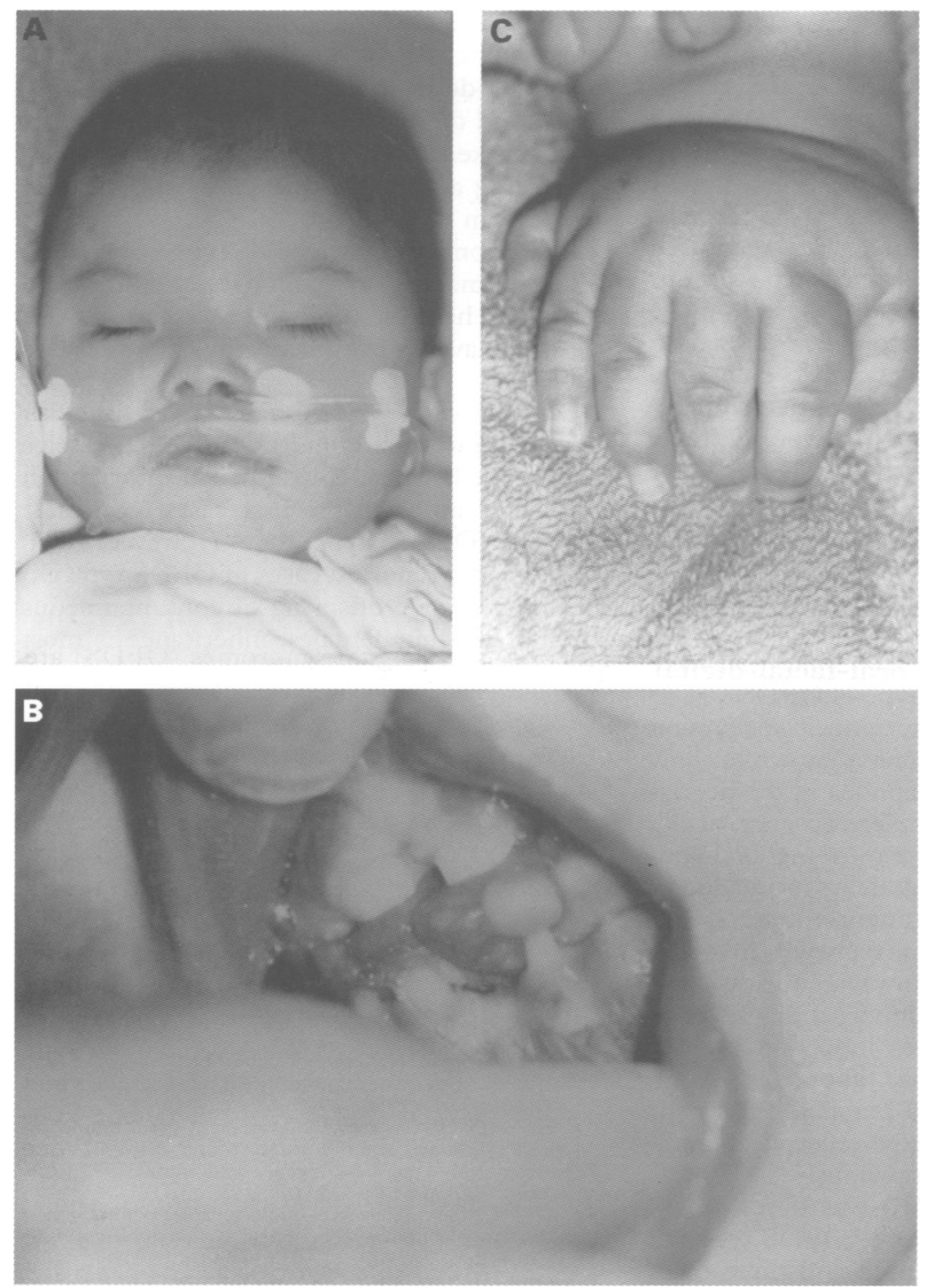

Figure 1 Clinical appearance of the patient at the age of 16 months. $(A)$ The patient's face showing eyelids closed because of bilateral microphthalmia. (B) Lobulated tongue with nodules, a thick midline alveolar frenulum, and irregular teeth. (C) Right hand showing postaxial polydactyly.
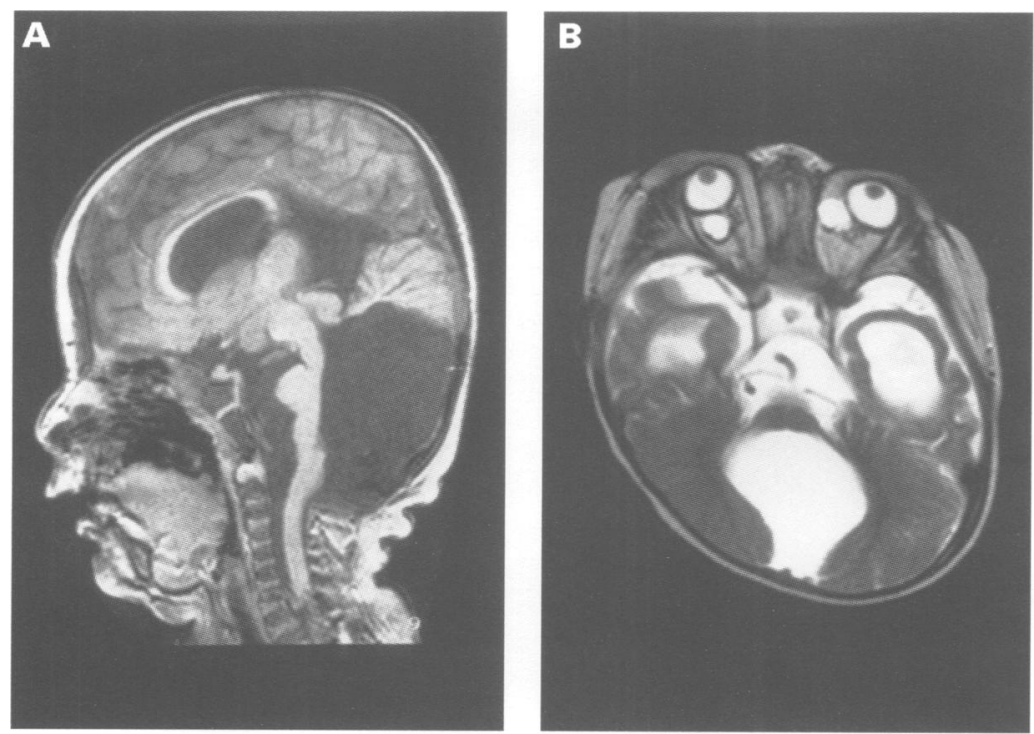

Figure 2 (A) Sagittal MRI T1 weighted image (TE $9 \mathrm{~ms}, T R 350 \mathrm{~ms}$ ) showing agenesis of the cerebellar vermis, posterior fossa cyst, and hypoplasia of the splenium corporis callosi. (B) Axial MRI T2 weighted image (TE $112 \mathrm{~ms}$, TR $4000 \mathrm{~ms}$ ) showing bilateral microphthalmia and retrobulbar cysts. the first report of OFDS type IX in 1992, four additional cases have been reported..$^{2-5}$

We report another case of OFDS type IX with central nervous system (CNS) anomalies (Dandy-Walker malformation and hydrocephalus) and retrobulbar cysts. Dandy-Walker malformation and retrobulbar cysts have not been reported previously as features of OFDS type IX. Our case had frequent apnoeic spells immediately after birth which were relieved by neurosurgical treatment for hydrocephalus.

\section{Case report}

The patient, a girl, was admitted to hospital for long term medical care when she was aged 13 months. She was the first and only baby of healthy and non-consanguineous parents. There was no family history of any abnormality suggestive of OFDS. She was recognised to have hydrocephalus at 9 months' gestation. She was born at 39 weeks' gestation by vaginal delivery. The birth weight was $2486 \mathrm{~g}(-1.5$ $\mathrm{SD})$, length $47 \mathrm{~cm}(-1.0 \mathrm{SD})$, and head circumference $32 \mathrm{~cm}$ (-0.8 SD). Multiple malformations observed at birth included a flat nasal bridge, hypertelorism, bilateral microphthalmia, low set ears, a prominent forehead, a posterior cleft palate, lobulated tongue with nodules, multiple thick midline alveolar frenula, and postaxial polydactyly of the hands and right foot (fig 1). The skin was normal with no milia, except for a haemangioma on the neck. Asphyxia was present at birth (Apgar scores were 3 at one minute and 6 at five minutes). Apnoeic spells and generalised convulsions appeared soon after birth. Her blood glucose and electrolytes were in the normal range. Administration of anticonvulsant medication reduced the convulsions but the apnoeic spells continued. Bronchoscopy showed a hypoplastic epiglottis. CT scan of the head showed cystic dilatation of the fourth ventricle occupying the posterior fossa and agenesis of the cerebellar vermis, which are compatible with Dandy-Walker malformation. Ophthalmological examination showed bilateral microphthalmia associated with optic disc coloboma, and dysplasia and partial detachment of the retina. Photographs of the retina were not taken because of a cloudy cornea. Her developmental milestones were severely retarded.

On admission to our hospital (aged 13 months), her weight was $8.4 \mathrm{~kg}$ (-0.7 SD), height $67 \mathrm{~cm}(-3.0 \mathrm{SD})$, and head circumference $45.5 \mathrm{~cm}$ (+0.2 SD). She was not able to raise her head and was floppy. MRI of the head on admission showed a Dandy-Walker cyst, hydrocephalus, and hypoplasia of the splenium corporis callosi. Bilateral microphthalmia and retrobulbar cysts were also observed on MRI (fig 2). Frequent apnoeic spells accompanied by shallow and rapid breathing continued after admission. One month later, a cystoperitoneal shunt was implanted for treatment of hydrocephalus and relief of apnoeic spells. The apnoeic spells gradually decreased after the surgery. However, she suffered from recurrent bacterial pneumonia and died on the 117 th day in hospital. Her karyotype was normal $(46, X X)$. Necropsy was not performed. 


\section{Discussion}

Gurrieri et al ${ }^{1}$ first reported two male sibs with manifestations of OFDS type II and retinal abnormalities. Since then, Jamieson and Collins, ${ }^{2}$ Nevin et al, ${ }^{3}$ Stevens and Marsh, ${ }^{4}$ and Sigaudy $e t$ a $\bar{l}$ have reported additional similar cases (OFDS type II and retinal abnormalities). This new type of OFDS was recognised as OFDS type IX. ${ }^{7}$ The phenotype of our patient resembled OFDS type I based on the oral, facial, and digital anomalies. However, there was also bilateral optic disc coloboma and retinal dysplasia with partial detachment, suggesting a diagnosis of OFDS type IX (table 1). Additional features in our case were Dandy-Walker malformation and retrobulbar cysts observed on MRI (fig 2). Dandy-Walker malformation has not been reported previously in OFDS type IX, although it has been noted in other types of OFDS including types I, II, III, IV, and VI. ${ }^{8}$ In contrast, retrobulbar cysts have not been reported in any type of OFDS.

Our patient had episodic apnoeic spells soon after birth. Joubert syndrome is known to show episodic tachypnoea and apnoea in the neonatal period, partial or complete absence of the cerebellar vermis, jerky eye movements, hypotonia, and developmental delay. Polydactyly, chorioretinal coloboma, tongue tumours, and cystic kidneys have been reported in some cases of the syndrome. ${ }^{9}$ However, our case had features which did not support a diagnosis of Joubert syndrome, such as lobulated tongue, multiple alveolar frenula, abnormal teeth, hypertelorism, and frontal bossing. Treatment of hydrocephalus gradually relieved the apnoeic spells as described previously. ${ }^{1011}$

Mental retardation (MR) was described in five of seven reported cases of OFDS type IX, in which two cases were mild and three cases had severe MR (table 1). CNS abnormalities were observed in two severe $M R$ cases and one mild MR case. A patient reported by Jamieson and Collins ${ }^{2}$ had atrophy of the frontal and parietal lobes with poor grey-white differentia- tion and died at 2 months of cardiorespiratory arrest. Our case had severe psychomotor developmental delay, repeated serious respiratory arrest, and died at 17 months. Both cases had quite marked cerebral abnormalities and died at a young age, suggesting the possibility of a severe form of OFDS type IX. However, a 22 year old woman reported by Nevin $e t a{ }^{\beta}$ had no CNS anomalies, no mental retardation, and height and head circumference were normal, so she may have had a mild form of the disease (table 1).

Gurrieri et $a l^{1}$ were unable to distinguish between autosomal and $\mathrm{X}$ linked recessive inheritance because of insufficient information when they reported the first cases (two male sibs) of OFDS type IX. However, with subsequently reported cases of OFDS type IX, including a male offspring of consanguineous parents and four females, inheritance is most likely autosomal recessive.

1 Gurrieri F, Sammito V, Ricci B, Iossa M, Bellussi A, Neri G Possible new type of oral-facial-digital syndrome with retinal abnormalities: OFDS type (VIII). Am f Med Genet 1992;42:789-92.

2 Jamieson R, Collins F. Oral-facial-digital syndrome and retinal abnormalities with autosomal recessive inheritance. Am ₹ Med Genet 1993;47:304-5.

3 Nevin NC, Silvestri J, Kernohan DC, Hutchinson WM. Oral-facial-digital syndrome with retinal abnormalities: Oral-facial-digital syndrome with retinal abnormalities: OFDS type IX.

4 Stevens JL, Marsh JL. Ocular anomalies in the oral-facialdigital syndrome. F Pediatr Ophthalmol Strabismus 1994;31: 397-8.

5 Sigaudy S, Philip N, Gire C, Chabrol B. Oral-facial-digita syndrome with retinal abnormalities: report of a new case. Am F Med Genet 1996;61:193-4.

6 Toriello HV. Heterogeneity and variability in the oral-facialdigital syndromes. Am f Med Genet (Suppl) 1988;4:149-59.

7 Toriello HV. Oral-facial-digital syndromes, 1992. Clin Dysmorphol 1993;2:95-105.

8 Leao MJ, Ribeiro-Silva ML. Orofaciodigital syndrome type I in a patient with severe CNS defects. Pediatr Neurol 1995; I in a patient

9 Saraiva JM, Baraitser M. Joubert syndrome: a review. $A m \mathcal{F}$ Med Genet 1992;43:726-31.

10 Krieger AJ, Detwiler J, Trooskin S. Respiration in an infan with the Dandy-Walker syndrome. Neurology 1974;24: 1064-7.

11 Bromberger P, James HE, Saunders B, Schneider H Sudden infant apnea and insidious hydrocephalus. Child's Nerv Syst 1988;4:241-3. 